\title{
Transient Stability Enhancement and Critical Clearing Time Improvement for Kurdistan Region Network using Fact Configuration
}

\author{
Tana Taher Azeez \\ Postgraduate student \\ ${ }^{1}$ Directorate of Transmission, Ministry of Electricity \\ Department of Electrical, College of Engineering, \\ University of Salahaddin, Erbil, Kurdistan Region, Iraq \\ tana.azeez@su.edu.krd
}

\author{
Ameen Abbas Abdelfattah \\ Supervisor \\ ${ }^{2}$ Department of Electrical, College of Engineering, \\ University of Salahaddin, Erbil, Kurdistan Region, Iraq \\ Ameen.abdulfatah@su.edu.krd
}

\begin{abstract}
The Electrical power system has become vast and more complex, so it is subjected to sudden changes in load levels. Stability is an important concept which determines the stable operation of the power system. Transient stability analysis has become one of the significant studies in the power system to ensure the system stability to withstand a considerable disturbance. The effect of temporary occurrence can lead to malfunction of electronic control equipment. The application of flexible AC transmission systems (FACTS) devices in the transmission system have introduced several changes in the power system. These changes have a significant impact on the power system protection, due to differences inline impedance, line current and voltage. On the distance relaying protection system to identify essential issues that protection engineers need to consider during the stages of design and operation of the protection system. Transient analysis can be conducted using a simulation software package. One of the commercial simulation software package used by industry worldwide is Siemens Power System Simulation for Engineering (PSS/E). The object of this work is to improve the Transient stability and to clear critical fault times of the Kurdistan Region Government (KRG) network by using optimal FACTS devices in different optimal locations under fault conditions.
\end{abstract}

Keywords: TS, CCT, FACT Devices, SVC, UPFC

\footnotetext{
*Corresponding author

Peer review under the responsibility of University of Baghdad.

https://doi.org/10.31026/j.eng.2020.10.04

2520-3339 ( 2019 University of Baghdad. Production and hosting by Journal of Engineering.

This is an open access article under the CC BY4 license http://creativecommons.org/licenses/by/4.0/).

Article received: $3 / 11 / 2019$
}

Article accepted:13/6/2020

Article published:1/10/2020 
تعزيز الاستقرار العابرة وتحسين وقت التبادل النقدي لثبكة اقليم الكوردستان باستخدام تثكيلات الحقائق

$$
\begin{aligned}
& \text { أمين عباس عبد الفتاح } \\
& \text { مشرف مبرن }
\end{aligned}
$$

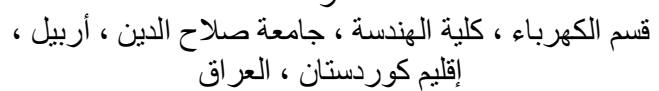

$$
\begin{aligned}
& \text { تانا ، طاهر ، عزيز } \\
& \text { قسم الكهرباء طالب در استات عليا }
\end{aligned}
$$

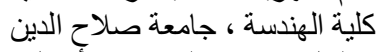

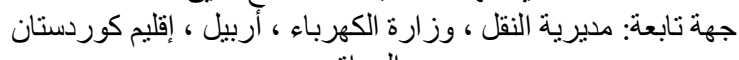

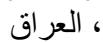

\section{الخلاصة}

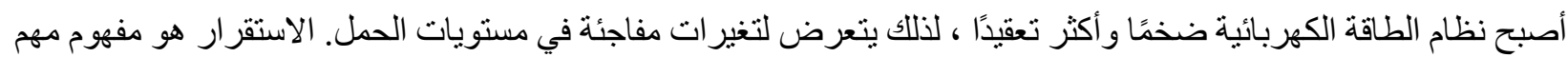

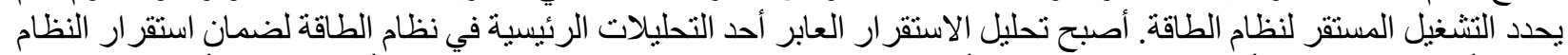

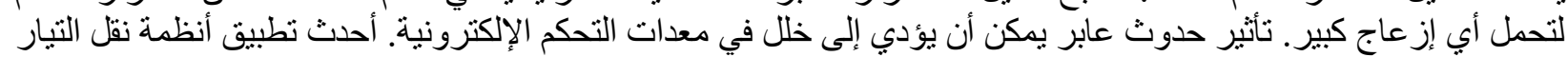

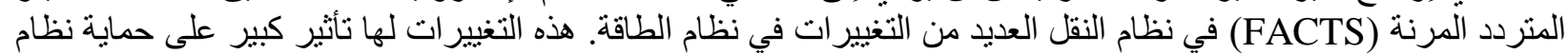

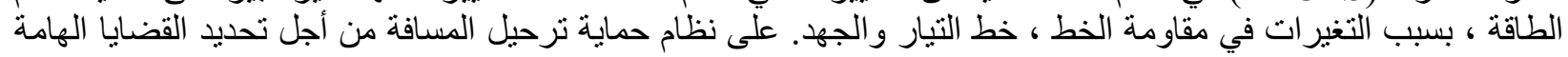

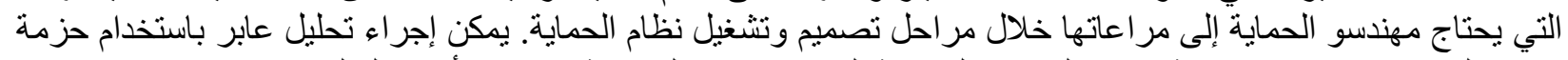

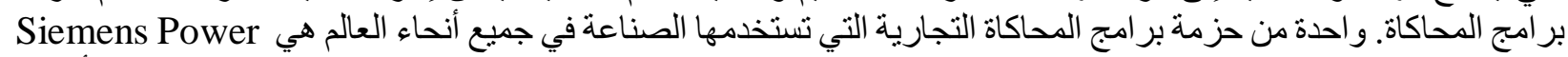
System Simulation for Engineering (PSS / E) الخلل الحرجة لثبكة حكومة إقليم كوردستان (KRG) عن طريق استخدام أجهزة FACTS المثلى في مو اقع أمثلية مختلفة تحت العت

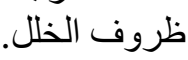
الكلمات الرئيسية : الاستقرار العابر ، وقت التخليص الحرج ، أجهزة خط نقل التيار المتردد المرنة ، معوض VAR الإحصائي ، وحدة تحكم موحدة لتدفق الطاقة.

\section{ABBREVIATION}

CCT - Critical Clearing Time

FACTS - Flexible Alternating Current Transmission System

FCT - Fast clearing time

KRG - Kurdistan Region Government

SVC - Statistic VAR Compensator

TSA - Transient Stability Analysis

UPFC - Unified Power Flow Controller

\section{INTRODUCTION}

Generally, Electrical strength system is commonly nonlinear system and a compound network, consists of three essential stages which are generation, transmission and distribution substations. The exporter central part is generation stations that transmit the electricity to the load. As a reference of growing power requesting, in transmission line sometimes may be loaded more than lines capacity at construction. Generation stage, on the electric power network, is the primary point of the power system for using synchronous generators to product electrical voltages. After production for increasing voltage using the set up a transformer before transferring it to minimizing the current in the lines in order to minimize the losses in the transmission lines. After the transmission, the voltage is stepped down using step down transformers that are distributed consequently. An unexpected massive disturbance contains faults, clearing of faults, surprising load changes and persistent or uncontrollable tripping of lines and generators. 
The transient stability is happening when the maximum power is transferred during the system when there is not any loss of balance under slight disturbance. Many factors causing transient stability like the strength of the transmission network within the system in and the times to adjacent systems working units, containing inertia of the rotating parts, the electrical properties such as magnetic saturation characteristics of the stator and rotor. Critical clearing time CCT is a significant parameter in TSA of the power system. When the maximum permissible time through the fault when occurring in power system before losing the synchronous is called CCT. The (FCT) fault clearing time is putting randomness in the system. The KRG $400 \mathrm{KV}$ and $132 \mathrm{kV}$ grid networks as shows in Fig.1 last updated and approved from MOE, faced with series of defiance like voltage instability, long transmission lines, the environment of transmission lines, high power losses.

The reason for this paper is to improve transient stability and critical fault clearing time in the KRG network by using FACTs devices by using PSS/E software when it was licensed by the government. In FACTs Devices, we choose (SVC and UPFC) as the best solution in our network for now to increase power transfer capability.

(To'aima et al., 2015)he investigated that STATCOM was planned to increase the apparent power loss and explain voltage fall issue of the IEEE 5bus standard system, the result has been done by using less possible size of the reactive power injected or absorbed by the STATCOM devices, while sustaining the stability limits in order to decrease the projected installation cost of STATCOM devices. (Hassan et al., 2019) The purpose of this study is to sustain sufficient power for higher heavy loads where possible and accurate amount of load shedding while keeping the load under the accessible power threshold. The main duties are saved ultimately without any disturbance likely. The output solves the efficiency and practicality of the applied method for probable uses in power systems.

(Abd Al Hassan and Tuaimah, 2020)Investigates one of the most promising FACTS devices, UPFC is used to achieve the fundamentals (voltage regulation, reactive power and power flow controller) to make the system more efficient and reliable. The result can show the number of UPFC is increase with increase load at (15\% and 20\%) because one UPFC cannot reduce from overload in lines so by using tow unit of UPFC device in different position can improve maximum load ability and minimum line losses.

The motivation behind this paper is to survey and improve the voltage profile in weak buses on the KRG network by using SVC (Reactive Power Control) (Husein and AbdulFatah, 2016). This investigation is about improvements of enactment are planned applied on the interconnected $400 \mathrm{kV}, 50 \mathrm{~Hz}$ Kurdistan and Iraq power systems using $\pm 500 \mathrm{kV}, 300 \mathrm{MW}$ HVDC link.

(Roberts et al., 2015) In this investigative show, the approximation of the (CCT) is resulting from the direct strategies of stability of the energy system. This Equation is designed to combine as many possible characteristics of transient stability analysis as possible, like different fault areas and different network circumstances after the failure. The objective of this calculation is to resolve trends instability (in terms of CCT) of energy systems under the system parameter change. 
(Mohammed, 2019) Is considered the essential (critical) clearing time of synchronous machines in the power systems, when the non-salient pole and salient poles of synchronous machine model are using mathematical equations in power system. CCT compared two models with various cases.

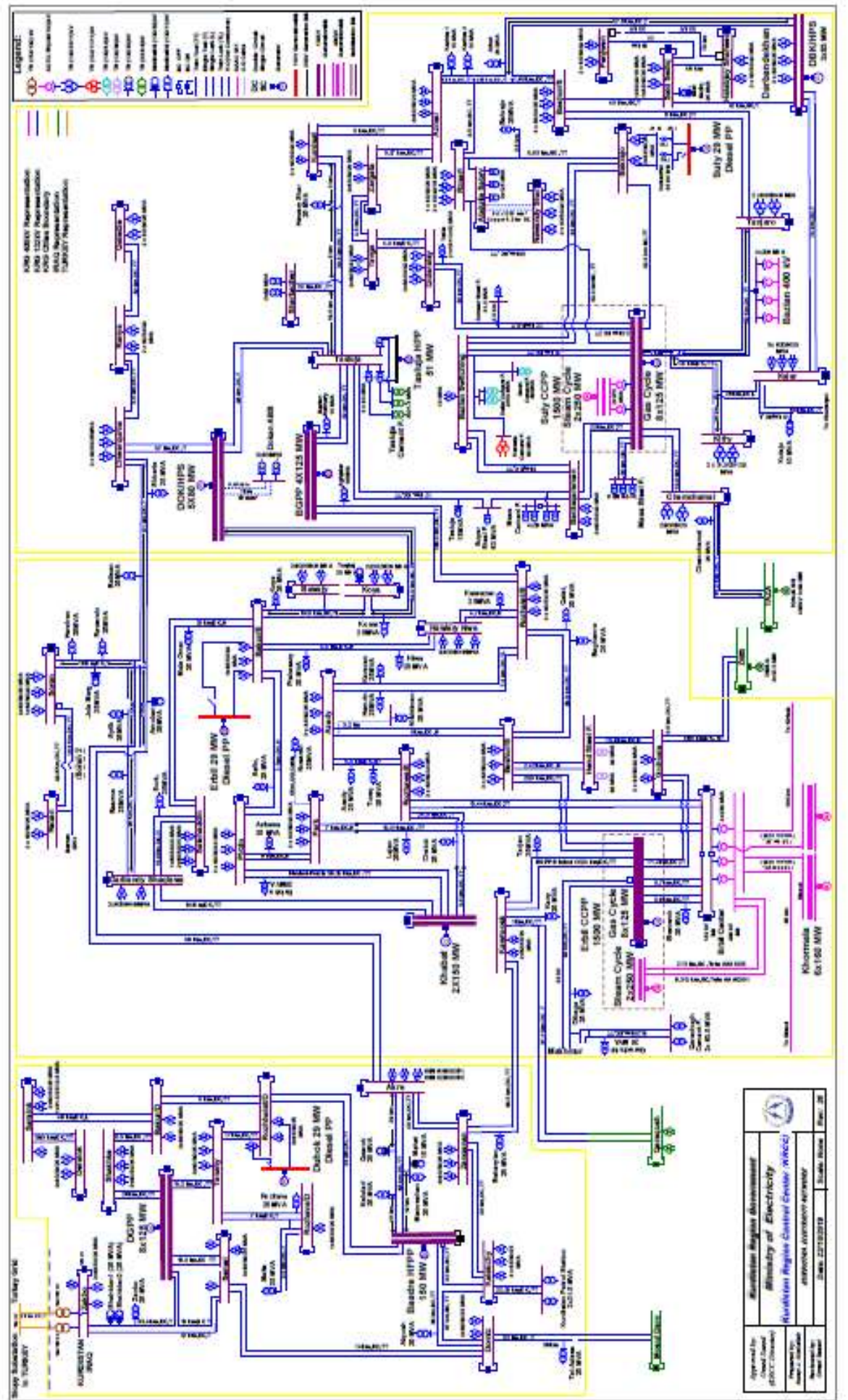

Figure 1 .KRG Network Single Line Diagram. 


\section{METHODOLOGY}

\subsection{Power System Stability}

When there is a physical disturbance in an electrical power system returning to operating condition without losing equilibrium is called power system stability (Kundur et al., 1994). It means the power system overall connected. In the practical group of generators connected when one of them is losing the synchronism the system not lose the stability.

Power system stability is classified into three types (steady state, dynamic and capable of a power system to transfer from point to another under the case of small load variation is steady state, transient) stability; dynamic stability is a type of rotor angle stability to discuss the stability when there is a significant disturbance.

\subsection{TRANSIENT STABILITY}

The capability of a power system to preserve of synchronism when it causes the transient fault is called transient stability; this disturbance is caused an epic trip of generators, rotor angles by nonlinear power angle linkage. The significant disruption causing loss of load and loss of generation units for returning to steady-state may be losing some generation units. (Sutter et al., 2015)

In KRG network case the system was stable, but when there is a bus fault, or one transmission line is out of work it makes the network unstable and the CCT change according to of type of responsibilities such as clearing in the result section. For simulating power system stability and output file, we can use PSS/E software.

\section{2.1 Swing Equation}

(Kundur et al., 1994)From SMIB the mathematical equations must be as:

$M \frac{d^{2} \delta}{d t^{2}}+D \frac{d \delta}{d t}=P_{m e c h}-P_{e l e c} \mathrm{~h}$

\section{When}

$M=$ inertia constant

$D=$ damping constant

Pmech $=$ mechanical power source

Pelec $=$ electrical power product

From the equivalent circuit the equations will be as:

$P_{e}=\frac{E^{\prime} E_{g}}{X_{T}} \sin \delta=P_{\max } \sin \delta$

The swing equation can be written as:

$\frac{2 H}{\omega_{0}} \frac{d^{2} \delta}{d t^{2}}=P_{m}-P_{\max } \sin \delta$ 


\subsubsection{Critical Clearing Time Calculatin}

The estimation stability in (CCT) is a critical component to preserve the stability of the power system. The maximum duration for occurring fault in a power system is called significant clearing time (CCT) when it sets randomly, if the time for CCT is less than the time for clearing fault CFT, it causes the loss of stability. The primary purpose is to calculate protection characteristics when required in power system. (Kundur et al., 1994)

$M \frac{d^{2} \delta}{d t^{2}}=P_{S}-P_{e}$

When the fault occurs $P_{e}=0$ hence the equation will be as:

$M \frac{d^{2} \delta}{d t^{2}}=P_{S}$

$\frac{2 \mathrm{H}}{\omega_{\mathrm{s}}} \frac{\mathrm{d}^{2} \delta}{\mathrm{dt}^{2}}=\mathrm{P}_{\mathrm{S}}$

$\frac{\mathrm{d}^{2} \delta}{\mathrm{dt}^{2}}=\frac{\omega_{\mathrm{s}}}{2 \mathrm{H}} \mathrm{P}_{\mathrm{S}}$

$\frac{\mathrm{d} \delta}{\mathrm{dt}}=\int_{0}^{\mathrm{t}} \frac{\omega_{\mathrm{s}}}{2 \mathrm{H}} \mathrm{P}_{\mathrm{s}} \mathrm{dt}=\frac{\omega_{\mathrm{s}}}{2 \mathrm{H}} \mathrm{P}_{\mathrm{s}} \mathrm{t}$

$\delta=\int_{0}^{\mathrm{t}} \frac{\omega_{\mathrm{s}}}{2 \mathrm{H}} \mathrm{P}_{\mathrm{s}} \mathrm{dt}=\frac{\omega_{\mathrm{s}}}{4 \mathrm{H}} \mathrm{P}_{\mathrm{s}} \mathrm{t}^{2}+\delta$

Let $\delta=\delta_{c}$ and $t=t_{c}$ so:

$\delta_{c}-\delta_{0}=\frac{\omega_{\mathrm{s}}}{4 \mathrm{H}} \mathrm{P}_{\mathrm{s}} \mathrm{t}^{2}$

At last

$t_{c}=\sqrt{\frac{2 H\left(\delta_{c}-\delta_{0}\right)}{\pi f \mathrm{P}_{\mathrm{s}}}}$

\section{3 fact Devices}

The flexible AC transmission system is a static device construct with the growing abilities of power electronic ingredient. Equipment's with high power level can change with various voltage scales. The comprehensive at initial points for network elements preferring the reactive power the parameters of the power system. The FACT devices are mainly classified:

1. Series controllers like Thyristor Controlled Series Capacitor (TCSC), Thyristor and Static Synchronous Series Compensator (SSSC). 
2. Shunt controllers like Static VAR Compensator (SVC), and Static Synchronous Compensator (STATCOM).

3. Combined series-series controllers

4. Mixed series-shunt controllers like Interline Power Flow Controller (IPFC), Unified Power Flow Controller (UPFC).

The main application of FACT devices is used for controlling power flow, compensating reactive power by increasing the ability of transmission lines, improving and conditioning power stability and quality, controlling of voltage stability, modification of sparks. Also, FACT devices having many advantages in transmission power system are summarized as follows:

1. Increasing transmission lines loading capacity.

2. Reactive power Decrease.

3. Decrease the spark voltage.

4. Damping of power pulses.

5. Stability system, ensuring.

6. Accessibility and Security.

7. Unwavering quality and economy activity.

\subsection{1 (SVC) Static VAR Compensator}

Shunt controller's electrical equipment, Static VAR Compensator (SVC) is the oldest type generating of the FACT device family, which is designed for refining fast-acting reactive power on a high-voltage electricity transmission line. SVC is an application using for voltage regulation, dynamic stability, damping Oscillations, and reducing voltage drop. SVC is most widely installed equipment's form FACT devices in the world which can be capable of supplying reactive power in the system for improving voltage stability. It connected to the transmission system directly for controlling voltage at weak buses occasionally it connected with the control of the transmission system as shown in Fig 2. (Khoa et al., 2017)

The modelling for SVC may be as (TCR-FC). In power system load is changed from time to time so that it causes confusion in the system, causing voltage instability. The essential appearances for SVC are voltage regulator and VAR switch mode. It's a stator device. Leading and lagging are terming for connecting SVC shunt devices. Worked on Voltage Profile Improvement of KR Power Network Using Reactive Power Control the result was improving stability of the system instantaneously. (Husein and AbdulFatah, 2016)

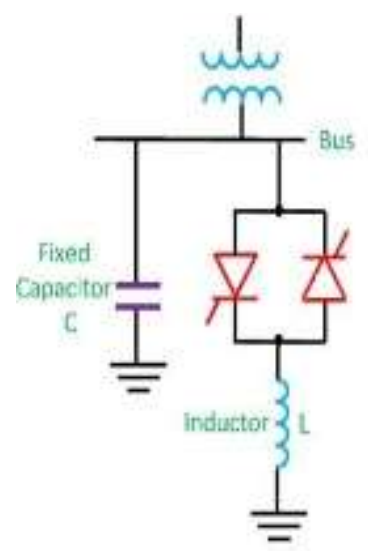

Figure 2. Static VAR compensator (SVC) model. 


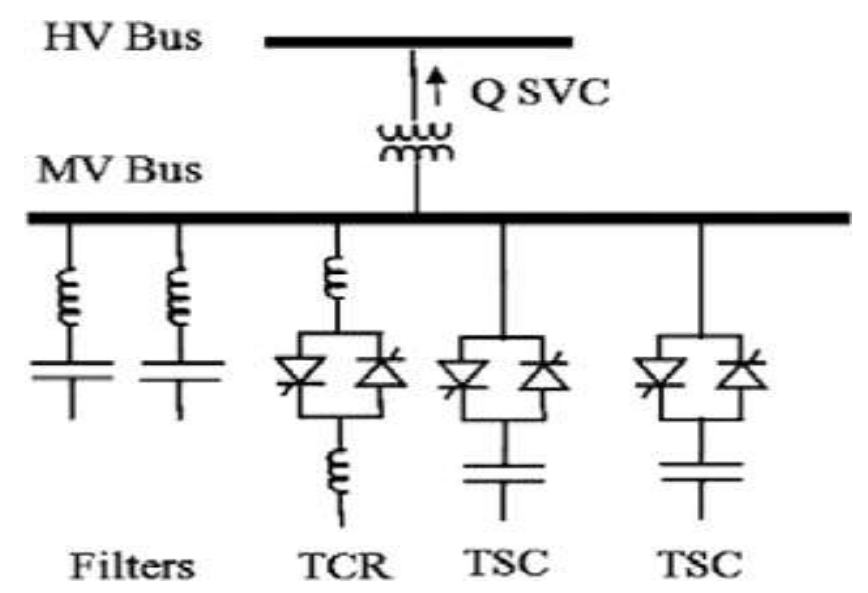

Figure 3. Static VAR compensator (SVC).

In our transmission line network, we suggest to use shunt fact devices SVC for improving voltage stability, voltage collapse and reactive power for increasing, transmitting power capacity, oscillation and damping by contingent on the optimal sites.

SVC is separated in two quantities one is static VAR generator the second is static VAR absorber when the output may be capacitive or inductive current to keep and regulate factors of electrical power system, especially the bus voltage, in general, is thyristor Controlled Reactor (TCR) for retaining reactive power and thyristor Switched Capacitor (TSC) for reactive power supplying as shown in figure (3). The basic idea of working SVC controlling system is (a) reactive power generation for (capacitive SVC) to low voltage; (b) reactive power absorbs for (inductive SVC) for high voltage. (Virk and Garg, 2013)

$I_{S V C}=j B_{S V C} V_{m}$

The reactive power injected at bus $\mathrm{m}$

$Q_{S V C}=Q_{m}=I_{S V C} V_{m}=-B_{S V C} V_{m}^{2}$

The susceptance $B_{S V C}$ Equivalent equation is given by:

$B_{S V C}=\frac{1}{X_{C} X_{L}} \frac{X_{C}-X_{L}\left[2\left(\pi-\alpha_{S V C}\right)+\sin 2 \alpha_{S V C}\right]}{\pi}$

The two thyristors is firing angle $\alpha S V C$

$X_{L}=w L$ 
$X_{C}=\frac{1}{W C}$

\subsubsection{UPFC (Unified Power Flow Controller)}

The UPFC is a device of the second generation of FACT devices which can use simultaneously for controlling several line parameters for power flow, such as (line impedance, voltage and phase angle). It was produced by combining two types of fact devices: The Static Synchronous Compensator (STATCOM) and the Static Synchronous Series Compensator (SSSC) as shown in Fig. 4 so that the UPFC is the best type between other FACT devices because it works as a shunt transformer by connecting to the transmission line system for improving steady-state stability, transient stability and increasing voltage stability. (Sebastian and Sajith, 2014). The fundamental principle of working UPFC is to controlling area time of dynamic compensation on AC transmission line when producing multi-functionality for improving problems in the power line system.

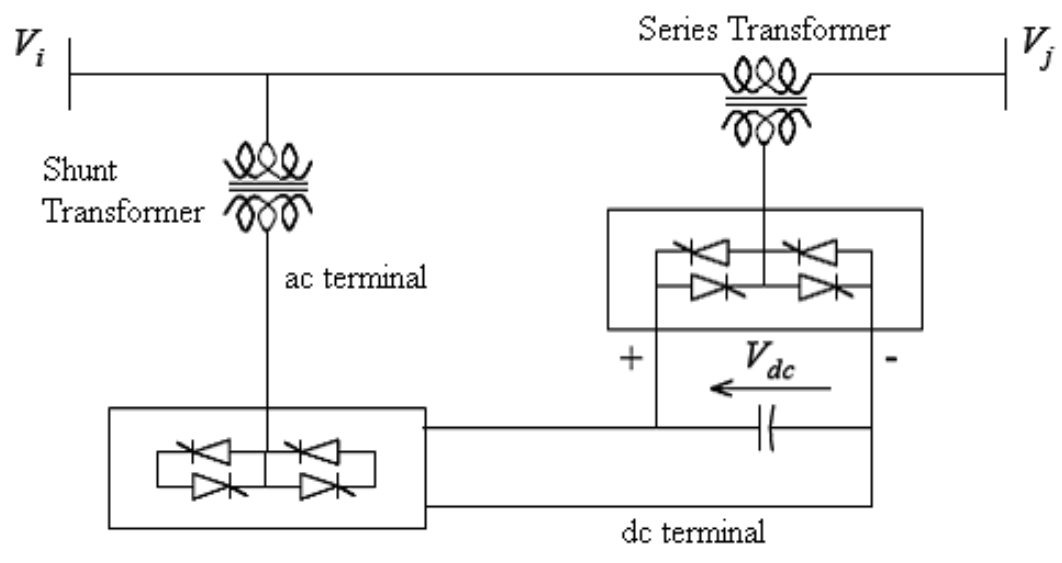

Figure 4. UPFC Control Model.

\section{RESULTS and Discussion}

\section{TRANSIENT STABILITY IMPROVEMENT MODELS}

In KRG network model, power flow. When it results from PSS/E software by using fixed slope decoupled Newton -Raphson. All bus Data of the system showing in Appendix A

WING BUS SUMMARY:

BUS\# X-- NAME --X BASKV PGEN PMAX PMIN QGEN QMAX QMIN

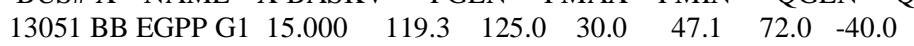

\subsection{WITHOUT FACT DEVICES}

For calculating transient stability in PSS/E first of all, we must convert the system to Dynamic system the process for converting the system to dynamic system for measuring CCT is in many steps when the system convert to dynamic we just putting the model of generators in our network 
we are using( GENROU) model and Exciter current model (SEXS) as shown in table (1) after that running the transient stability reading CCT, after that, we create three-phase fault in the system and reading CCT if the system remains stable we it means we do not have any problem, but if the order is not firm we must return back to dynamic data and changing the system till we get stability in the network this prose is shown in a flowchart in Fig. $\mathbf{5}$

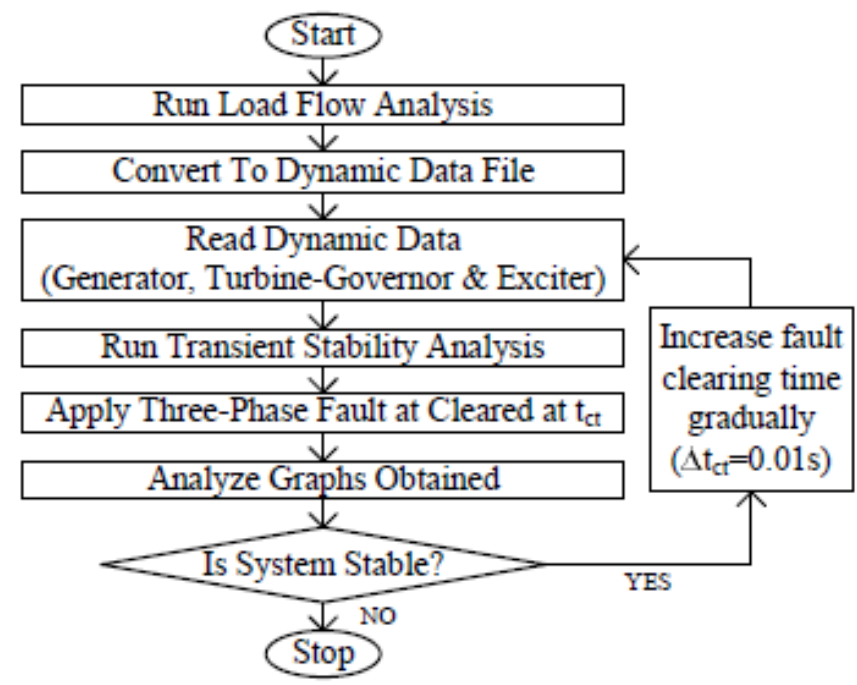

Figure 5. Flowchart of Transient Stability Analysis in PSS/E.

Table 1. GENROU model Data Inputting and SEXS model data.

\begin{tabular}{|c|c|c|c|c|c|c|}
\hline \multicolumn{3}{|c|}{ Model GENROU for machine at bus $14081^{\prime} 1{ }^{\prime}$} & \multicolumn{4}{|c|}{ Model SEXS for machine at bus 14083 ' 3 ' } \\
\hline \multirow[t]{2}{*}{ Model CONS } & \multicolumn{2}{|c|}{ Model ICONS Model VARS } & \multirow[t]{2}{*}{ Model CONS } & \multirow{2}{*}{\multicolumn{3}{|c|}{ Model ICONS Model VARS }} \\
\hline & $\begin{array}{c}\text { Con } \\
\text { Value }\end{array}$ & $\begin{array}{c}\text { Con } \\
\text { Description }\end{array}$ & & & & \\
\hline 1 & 1.9000 & Tdo $(>0)$ & & Con & & Con \\
\hline 2 & 0.0450 & $T$ do $(>0)$ & & Value & & Description \\
\hline 3 & 0.6500 & Tqo $(>0)$ & 1 & 0.1000 & TA/TB & \\
\hline \begin{tabular}{|l|}
4 \\
5
\end{tabular} & $\begin{array}{l}0.0880 \\
6.3300\end{array}$ & $\begin{array}{l}\text { T'qo }(>0) \\
H, \text { Inertia }\end{array}$ & 2 & 10.0000 & $\mathrm{~TB}(>0)$ & \\
\hline 6 & 0.0000 & D, Speed Damping & 3 & 100.0000 & $\mathrm{~K}$ & \\
\hline$\frac{7}{8}$ & $\begin{array}{l}1.9900 \\
1.8900\end{array}$ & $\begin{array}{l}\mathrm{Xd} \\
\mathrm{Xq}\end{array}$ & 4 & 0.1000 & TE & \\
\hline 9 & 0.1950 & Xd & 5 & 0.0000 & EMIN & \\
\hline \begin{tabular}{|l|}
10 \\
11
\end{tabular} & $\begin{array}{l}0.3850 \\
0.1350\end{array}$ & $\begin{array}{l}X q \\
X " d=X " q\end{array}$ & 6 & 3.0000 & EMAX & \\
\hline 12 & 0.1100 & $\mathrm{XI}$ & & & & \\
\hline 13 & 0.0817 & $S(1.0)$ & & & & \\
\hline 14 & 0.6474 & $S(1.2)$ & & & & \\
\hline
\end{tabular}

A- At natural casein our network, the system is stable. I have not any problem, and the critical clearing time CCT 0.2sec as shown in Fig.6. 


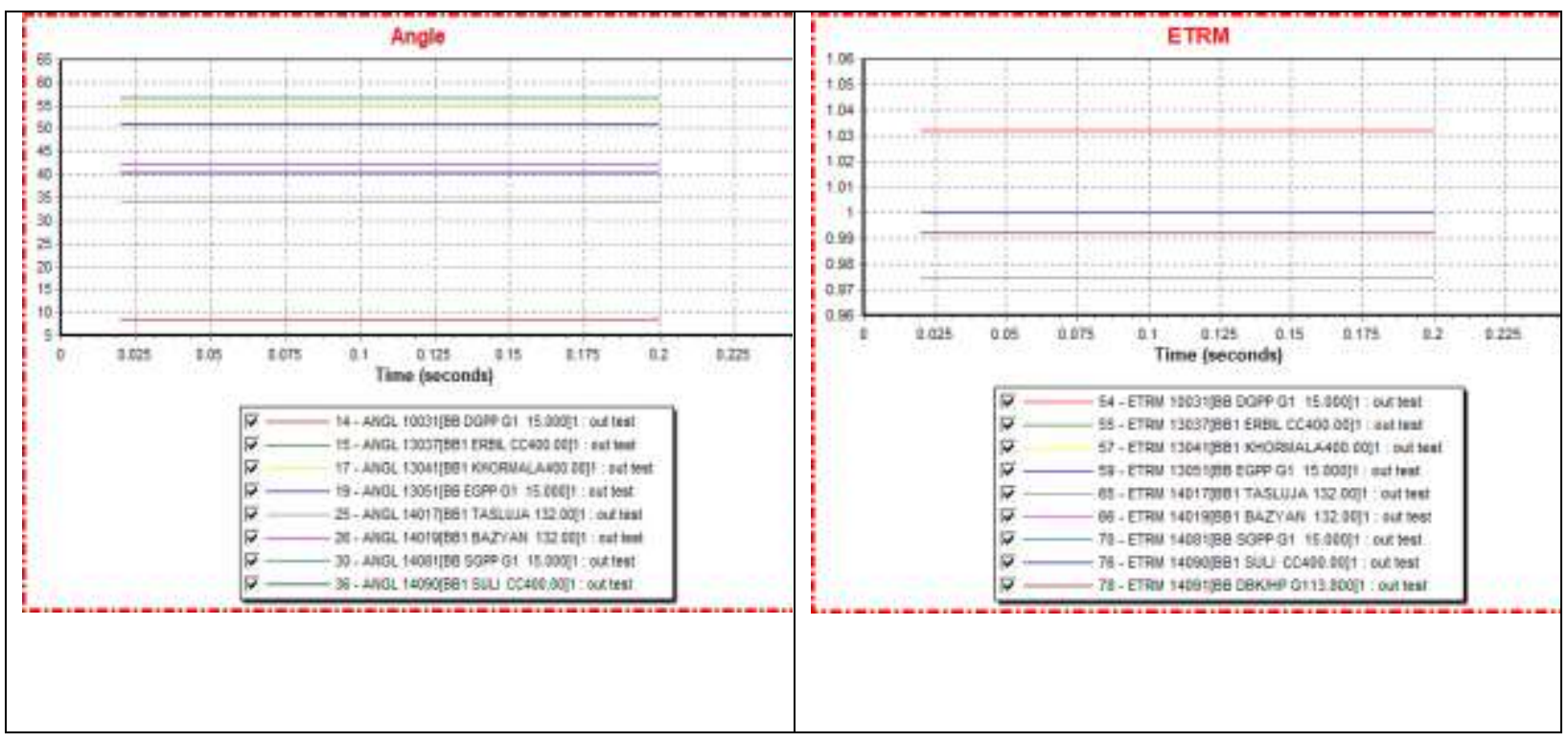

Figure 6. CCT Analyses at normal case.

B-When there is a three-phase fault in one bus such as Soran substation Bus, KRG network it will be out of the stable and the transient stability cannot be stable in one value. Shown in Fig.7

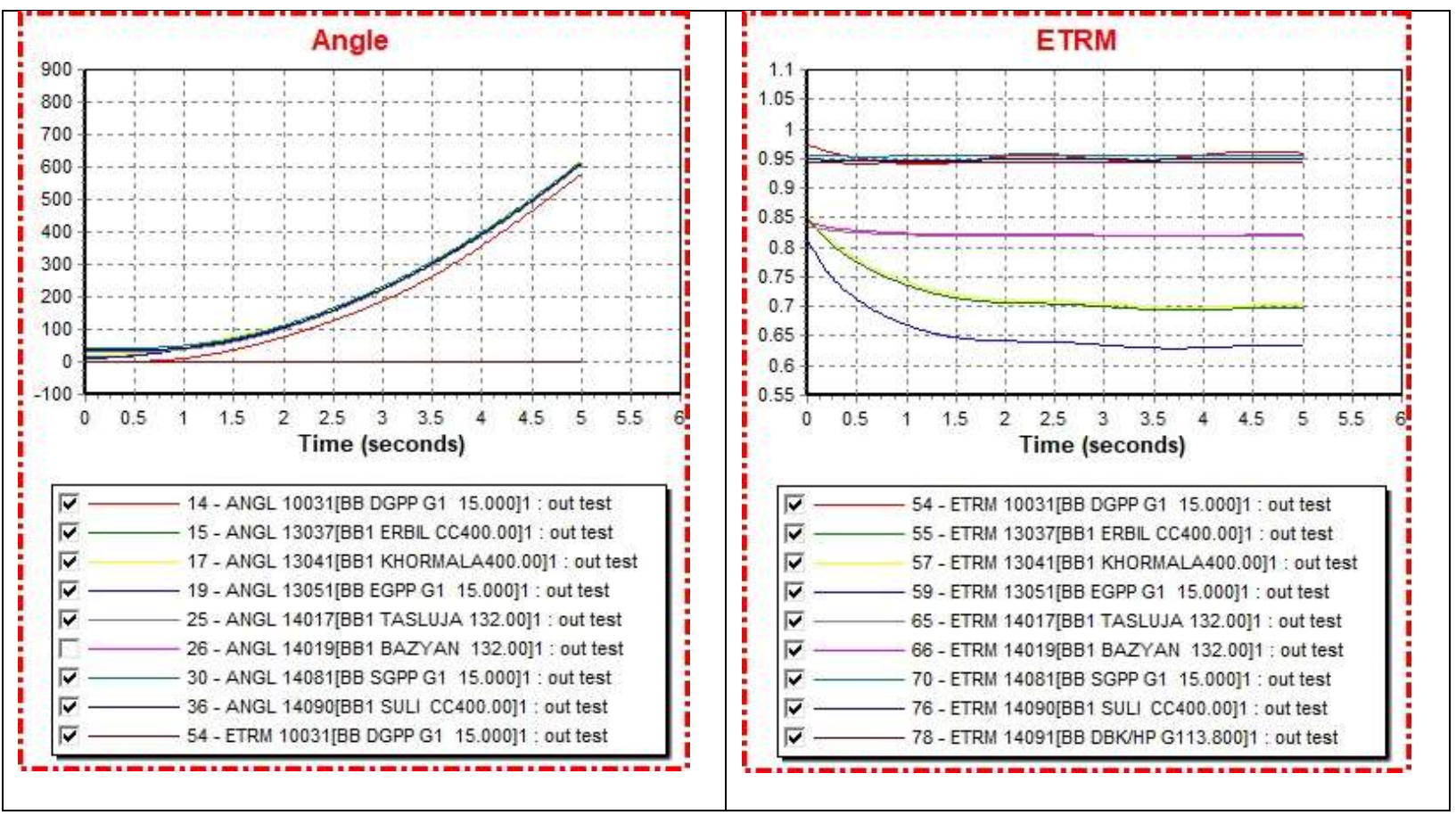

Figure 7. CCT with a fault on Shaqlawa-Soran line. 


\subsection{WITH FACT DEVICES}

\section{A- By connecting SVC}

At normal case we have any problem in the KRG network one of them under-voltage, overload, by Connecting SVC in parallel with EGPP bus the result for CCT will be between (0.1-0.25) and the under-voltage of many busses was increased. and the transient stability for calculating CCT is increasing as Fig.8

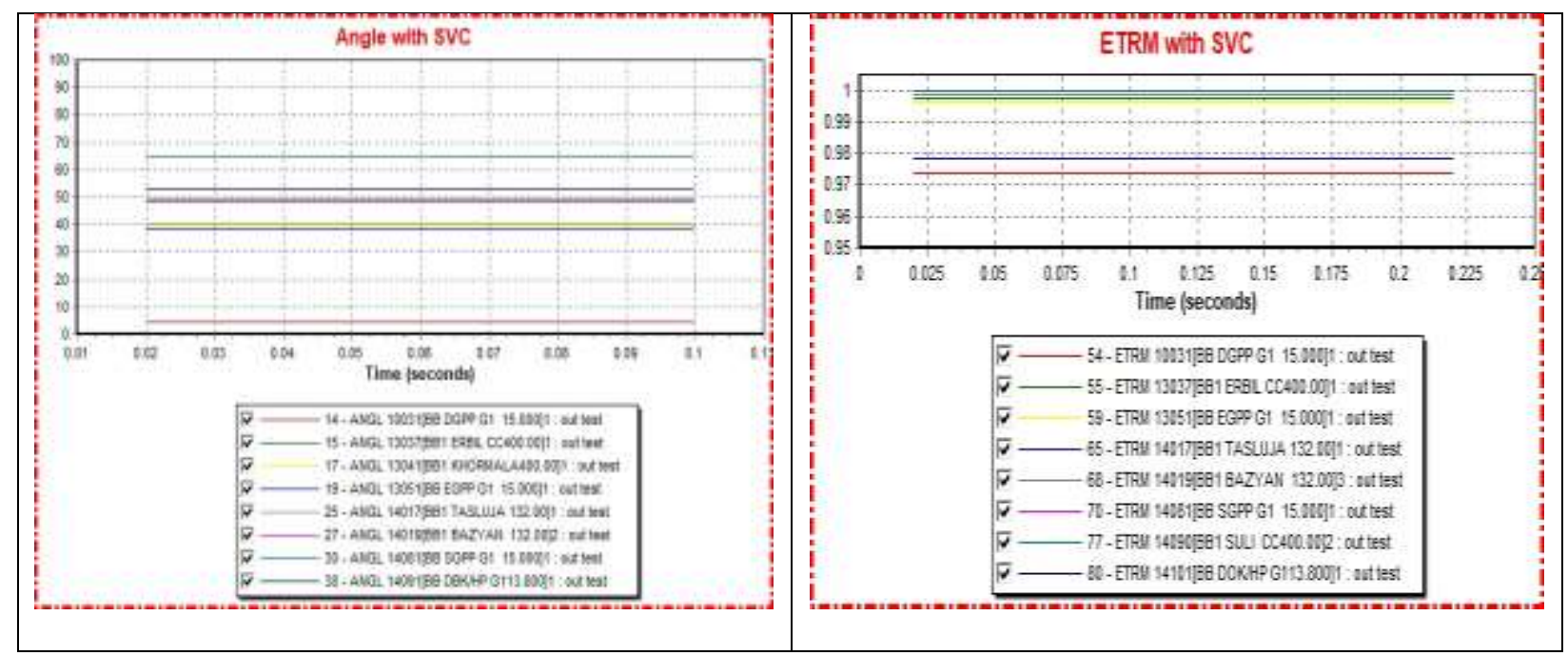

Figure 8. CCT with SVC.

\section{a. By connecting UPFC}

Connecting UPFC in series with EGPP bus the result for CCT will be between $(0.23$ 0.45)0.171pu as shown in Fig.9

By connecting UPFC in the KRG network many especially in Duhok and Soran area, many problems were solving such (overloading and under voltage) because the voltage in this area is very low it changed from $111 \mathrm{Kv}$ to $125 \mathrm{Kv}$.as shown in appendix $\mathrm{B}$. 


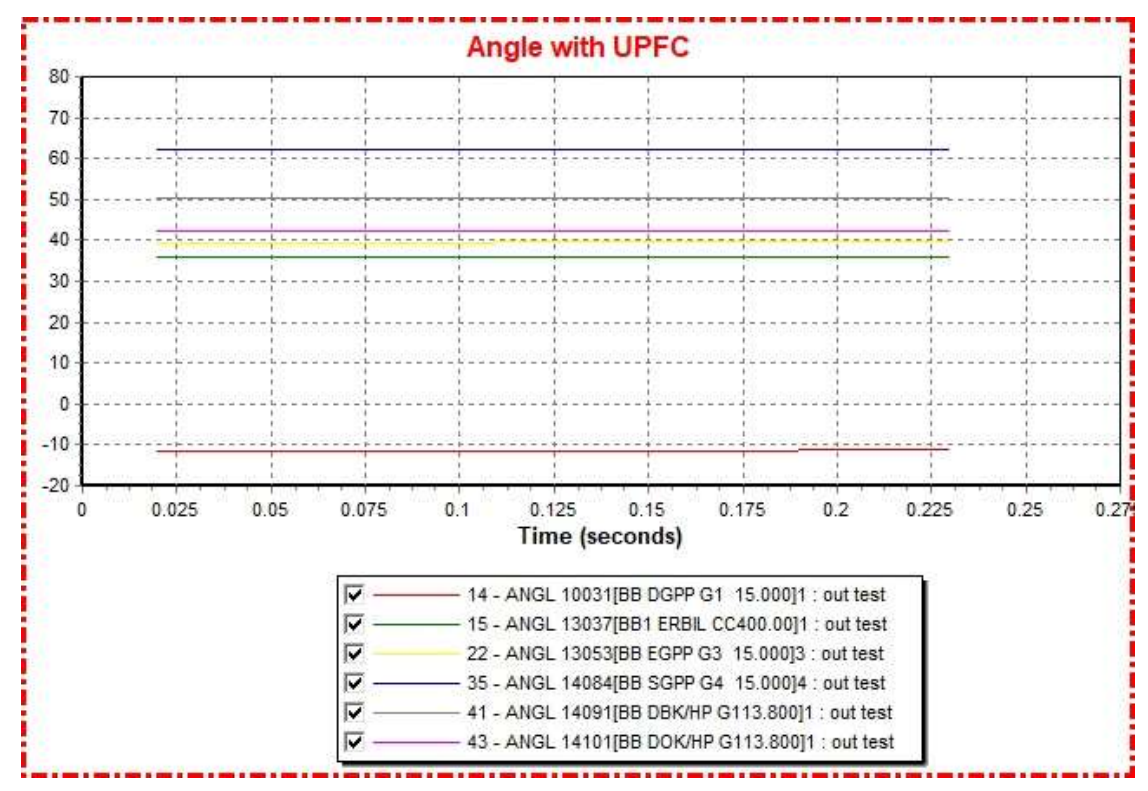

Figure 96. CCT with UPFC.

By this calculation, in result, we occur that connecting UPFC is much better for connecting to our KRG network. In our network having low voltage level in Duhok and Soran area if we using UPFC it will solve this problem and solving many other problems such as transient stability and dynamic stability. Also, SVC is a good compensator for improving our problem but comparing it with UPFC, UPFC is much better, but it's more costing than SVC as shown in table 2

Table 2: Comparison between SVC and UPFC

\begin{tabular}{|c|c|c|c|c|c|}
\hline FACTS & $\begin{array}{c}\text { Power System } \\
\text { Stability } \\
\text { Enhancement }\end{array}$ & Load Flow & $\begin{array}{c}\text { Voltage } \\
\text { Stability }\end{array}$ & $\begin{array}{c}\text { Transient } \\
\text { Stability }\end{array}$ & $\begin{array}{c}\text { Dynamic } \\
\text { Stability }\end{array}$ \\
\hline SVC & Yes & Low & High & Low & Medium \\
\hline UPFC & Yes & Medium & High & High & Medium \\
\hline
\end{tabular}

\section{CONCLUSION}

FACT devices are power electronics based reactive compensators that are connected in a power system and are capable of improving the power system transient performance and the quality of supply. Although individual compensations differ, all the two FACTS devices not only damp the system oscillations of the multi machine system but also reduce the oscillation settling times for generator Emf and rotor angle transient responses. This observation of KRG network is helpful to examine stability improvement in both the cases. This work can be extended to multi-machine system by using other types of FACTS controllers like SVC, UPFC etc. 


\section{REFERENCES}

- HASSAN, Y. F., RASHID, Y. G. \& TUAIMAH, F. M. 2019. Demand Priority in a Power System With Wind Power Contribution Load Shedding Scheme Based. Journal of Engineering, 25, 92-111.

- HUSEIN, T. S. \& ABDUlfATAH, A. A. 2016. Voltage Profile Improvement of KR Power Network Using Reactive Power Control. ZANCO Journal of Pure and Applied Sciences, 28.

- KHOA, N. M., HIEU, N. H. \& VIET, D. T. 2017. A Study of SVC's Impact Simulation and Analysis for Distance Protection Relay on Transmission Lines. Int. J. Electr. Comput. Eng, 7, 1686-1695.

- KUNDUR, P., BALU, N. J. \& LAUBY, M. G. 1994. Power system stability and control, McGraw-hill New York.

- MOHAMMED, I. J. 2019. Calculation the Critical Clearing Time CCT for Iraqi super grid in a fast manner of three-phase fault. journal of kerbala university, 17, 38-53.

- ROBERTS, L. G., CHAMPNEYS, A. R., BELL, K. R. \& DI BERNARDO, M. 2015. Analytical approximations of critical clearing time for parametric analysis of power system transient stability. IEEE Journal on Emerging and Selected Topics in Circuits and Systems, $5,465-476$.

- SEBASTIAN, L. \& SAJITH, R. 2014. Power Flow Control in A Transmission Line Using Unified Power Flow Controller. International Open Access Journal of Modern Engineering Research (IJMER), 4.

- SUTTER, J. R., NDERU, J. N. \& MURIITHI, C. M. 2015. Transient Stability Enhancement with Application of FACTS Devices. International Journal on Recent Technologies in Mechanical and Electrical Engineering, 2, 42-46.

- TO'AIMA, F. M., AL-AANI, Y. N. \& SALBI, H. A. A. 2015. Optimal location of static synchronous compensator (statcom) for ieee 5-bus standard system using genetic algorithm. Journal of Engineering, 21, 72-84.

- VIRK, P. S. \& GARG, V. K. 2013. Power system stability improvement of long transmission line system by using static VAr compensator (SVC). International Journal of Engineering Research and Applications, 3, 01-03. 


\title{
Appendix
}

\section{A. Load Flow at normal case and all bus data of KRG Network}

\author{
SIEMENS POWER TECHNOLOGIES INTERNATIONAL
}

50000 BUS POWER SYSTEM SIMULATOR--PSS(R) E-33.5.2

INITIATED ON TUE, DEC $102019 \quad 10: 44$

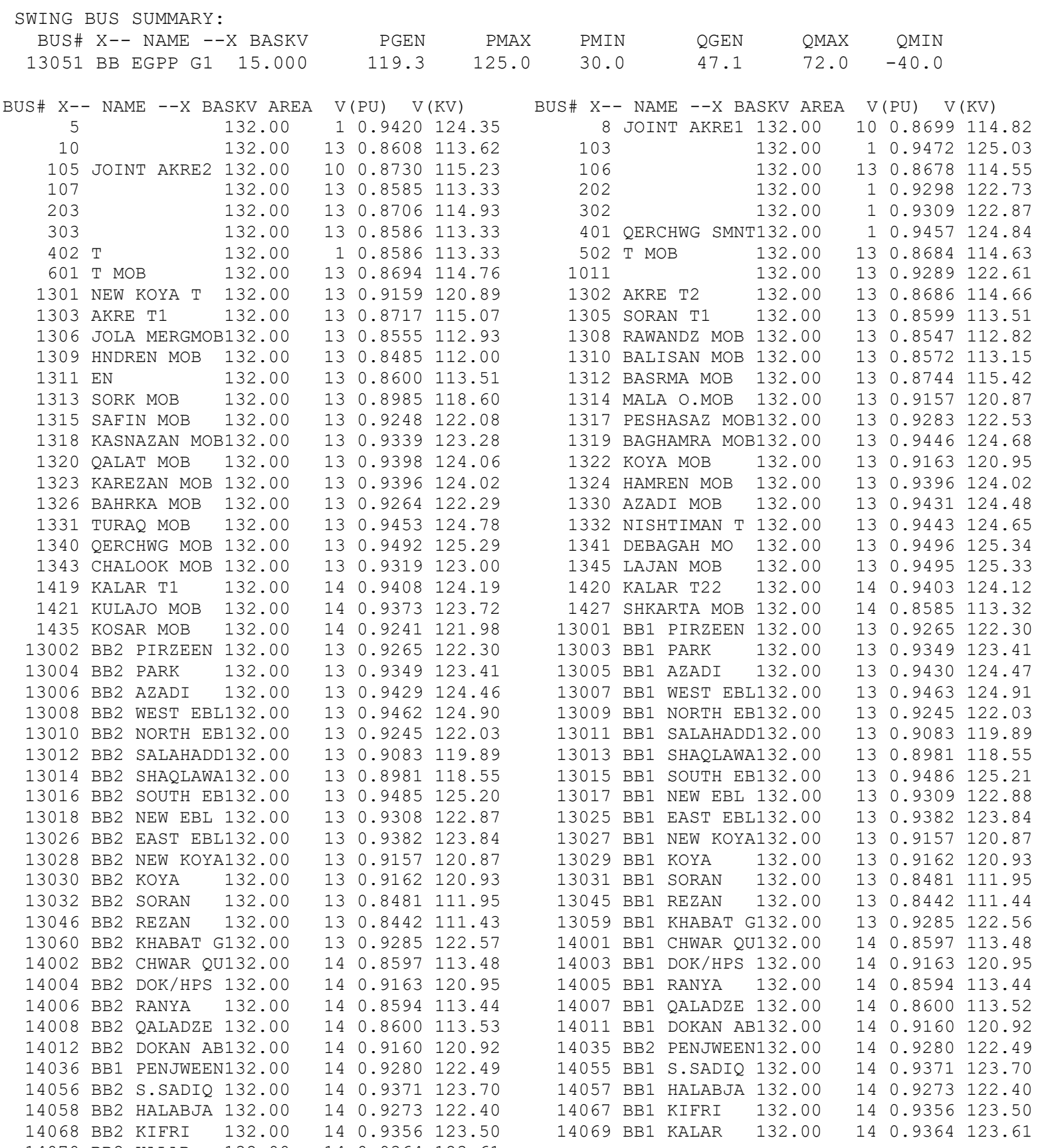




\begin{tabular}{|c|c|c|c|c|c|c|c|c|c|c|c|c|c|}
\hline BUS\# & $X^{--}$ & NAME - - & BASKV & AREA & BUS\# & $x--$ & NAME $--X$ & X BASKV & AREA & CKT & LOADING & RATING & PERCE \\
\hline & BB1 & DOK/HPS & 132 & 14 & 14018 & BB2 & TASLUJA & $132.00 *$ & 14 & 1 & 13 & 0 & 11 \\
\hline 3 & BB1 & DOK/HPS & 132.00 & 14 & 14018 & BB2 & TASLUJA & $132.00 *$ & 14 & 2 & 139.1 & 123.0 & 113. \\
\hline & 31 & SGPP & 132.00 & 14 & 14048 & B2 & GPP & $132.00 *$ & 14 & @1 & 1098.5 & 1000.0 & 109 \\
\hline
\end{tabular}

\section{B. When connecting Fact Devices}

\section{UPFC (100Mvar Duhok \& 150Mvar Soran)}

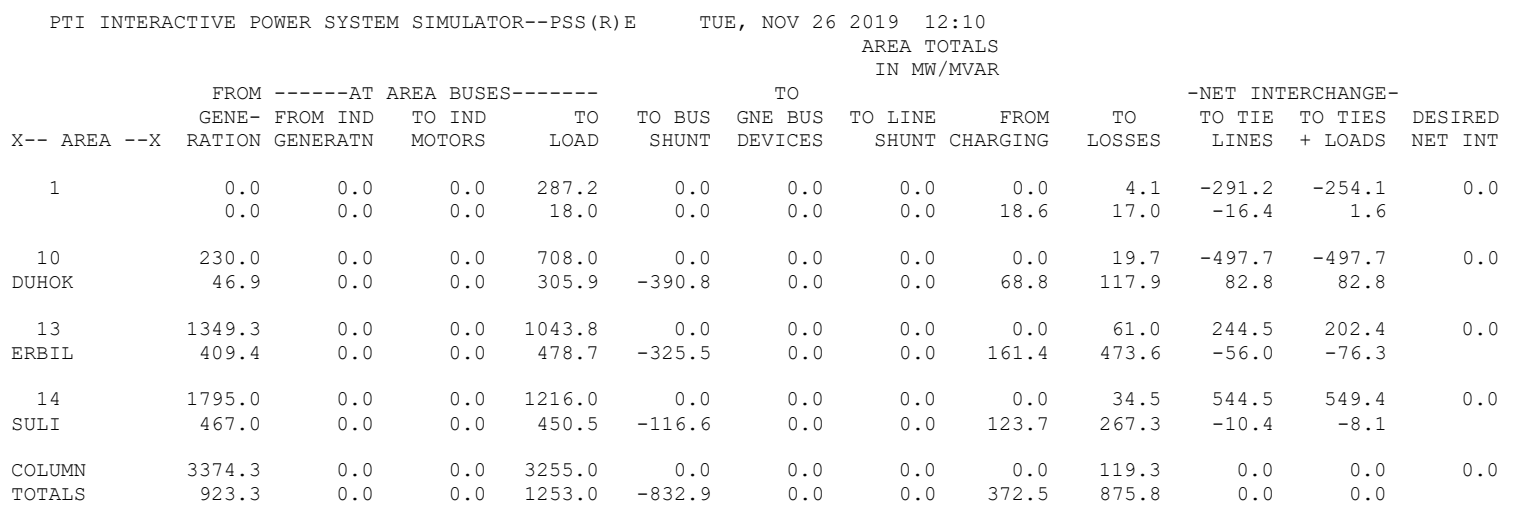

PTI INTERACTIVE POWER SYSTEM SIMULATOR--PSS(R)E TUE, NOV $26 \quad 2019$ 12:10

SUBSYSTEM LOADING CHECK (INCLUDED: LINES; BREAKERS AND SWITCHES; TRANSFORMERS) (EXCLUDED: NONE) MVA LOADINGS ABOVE $100.0 \%$ OF RATING:

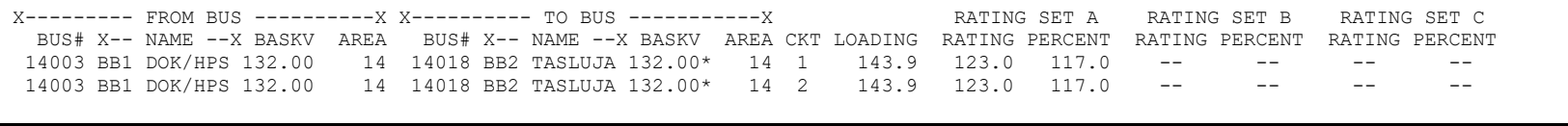

PTI INTERACTIVE POWER SYSTEM SIMULATOR--PSS(R)E TUE, NOV $26 \quad 2019$ 12:11

BUSES WITH VOLTAGE GREATER THAN 1.0500 :

$$
\begin{aligned}
& \text { BUS\# } \mathrm{X}-\mathrm{-} \text { NAME --X BASKV AREA } \mathrm{V}(\mathrm{PU}) \quad \mathrm{V}(\mathrm{KV}) \quad \text { BUS\# } \mathrm{X}-- \text { NAME - } \mathrm{X} \text { BASKV AREA } \mathrm{V}(\mathrm{PU}) \quad \mathrm{V}(\mathrm{KV}) \\
& \text { * NONE * }
\end{aligned}
$$

BUSES WITH VOLTAGE LESS THAN 0.9000 :

BUS\# X-- NAME --X BASKV AREA V(PU) V(KV) 1427 SHKARTA MOB $132.00 \quad 14 \quad 0.8805 \quad 116.23$ 14002 BB2 CHWAR QU132.00 $14 \quad 0.8820116 .43$ 14006 BB2 RANYA $132.00 \quad 14 \quad 0.8819116 .41$ 14008 BB2 QALADZE $132.00 \quad 14 \quad 0.8831 \quad 116.58$
BUS\# X-- NAME --X BASKV AREA V(PU) V(KV) $\begin{array}{lllllll}14001 & \text { BB1 CHWAR QU132.00 } & 14 & 0.8821 & 116.43\end{array}$ $\begin{array}{lllllll}14005 & \text { BB1 RANYA } & 132.00 & 14 & 0.8819 & 116.41\end{array}$ $\begin{array}{lllllll}14007 & \text { BB1 QALADZE } & 132.00 & 14 & 0.8831 & 116.57\end{array}$ 